\title{
Effects of Melt Temperature and Hold Pressure on the Tensile and Fatigue Properties of an Injection Molded Talc-Filled Polypropylene
}

\author{
Yuanxin Zhou, P.K. Mallick \\ Center for Lightweighting Automotive Materials and Processing, University of Michigan-Dearborn, \\ Dearborn, Michigan 48128
}

\begin{abstract}
This article examines the effects of melt temperature and hold pressure on the static tensile and fatigue behavior of an injection-molded $\mathbf{4 0} \mathrm{wt} \%$ talc-filled polypropylene. Injection molding caused anisotropy in the material. Both yield strength and fatigue strength were higher in the flow direction. The presence of weld line caused a large reduction in yield strength and fatigue strength. For specimens in the flow direction, both yield strength and fatigue strength increased with increasing hold pressure, but they were relatively insensitive to melt temperature. For specimens normal to the flow direction, both yield strength and fatigue strength increased with increasing hold pressure and decreased with increasing melt temperature. For specimens containing a weld line, the yield strength and fatigue strength increased with increasing hold pressure as well as increasing melt temperature. The observed differences in properties are explained in terms of the skin-core morphology, which was influenced by both melt temperature and hold pressure. POLYM. ENG. SCI., 45:755-763, 2005. @ 2005 Society of Plastics Engineers
\end{abstract}

\section{INTRODUCTION}

Mineral-filled polypropylene has many potential applications in automobiles, appliances, and other commercial products where creep resistance, stiffness, and some toughness are demanded in addition to weight and cost savings. The mechanical behavior of mineral-filled polypropylene and short glass or carbon fiber-reinforced polypropylene has been the subject of many studies over the last few years [1-5]. Limited research has also been done to examine the relationship between their tensile properties, microstructure, and processing conditions [6-15]. A few of these studies have focused on talc-filled polypropylene. For example, Davé and Chundury [12] used a "design of experiment"

Correspondence to: P.K. Mallick; e-mail: pkm@umich.edu Contract grant sponsors: Ford Motor Company, TRW Education Foundation.

DOI 10.1002/pen.20301

Published online in Wiley InterScience (www.interscience.wiley.com).

(C) 2005 Society of Plastics Engineers approach to determine the effects of several injection molding conditions on the tensile strength of talc-filled polypropylene. They observed that tensile strength increased with both barrel temperature as well as mold temperature. Guerrica-Echevaría et al. [13] found that modulus and yield strength of $10 \%, 20 \%$, and $40 \%$ talc-filled polypropylenes were affected slightly with increasing mold temperature as well as increasing melt temperature, but injection rate and screw rotation speed did not have much effect on these two properties. However, screw rotation speed had a very severe effect on the ductility of talc-filled polypropylenes. DiezGutierrez et al. [14, 15] studied the heterogeneity and anisotropy of injection-molded talc-filled polypropylene discs using dynamic mechanical analysis and thermomechanical analysis. They reported a high degree of anisotropy in these discs due to preferred orientation of talc particles in the flow direction.

In this article we report the effects of two injection molding parameters, namely, melt temperature and hold pressure, on the tensile and stress-controlled fatigue properties of a $40 \mathrm{wt} \%$ talc-filled polypropylene. In an earlier article [16], we reported the effects of specimen orientation, stress concentration, weld lines, and frequency on the stresscontrolled fatigue properties of the same material. To our knowledge, the effect of injection molding parameters on the fatigue behavior of talc-filled polypropylene has not been studied in the past.

\section{EXPERIMENTAL}

The material investigated in this study was a $40 \mathrm{wt} \%$ talc-filled polypropylene homopolymer available from Ferro (Cleveland, $\mathrm{OH}$ ) under the grade name TP40AC52BK. The average flow rate of this material, as reported by Ferro, was $6.8 \mathrm{~g} / 10 \mathrm{~min}$ (measured under ASTM D-1238 condition). The melting point of the polypropylene matrix was $160^{\circ} \mathrm{C}$. Square plates, $150 \times 150$ $\mathrm{mm}$, were injection-molded from the pellets in a single edge-gated mold with a central 25-mm diameter core (Fig. 1). The plate thickness was $2.5 \mathrm{~mm}$. A 90-ton Toyo injec- 


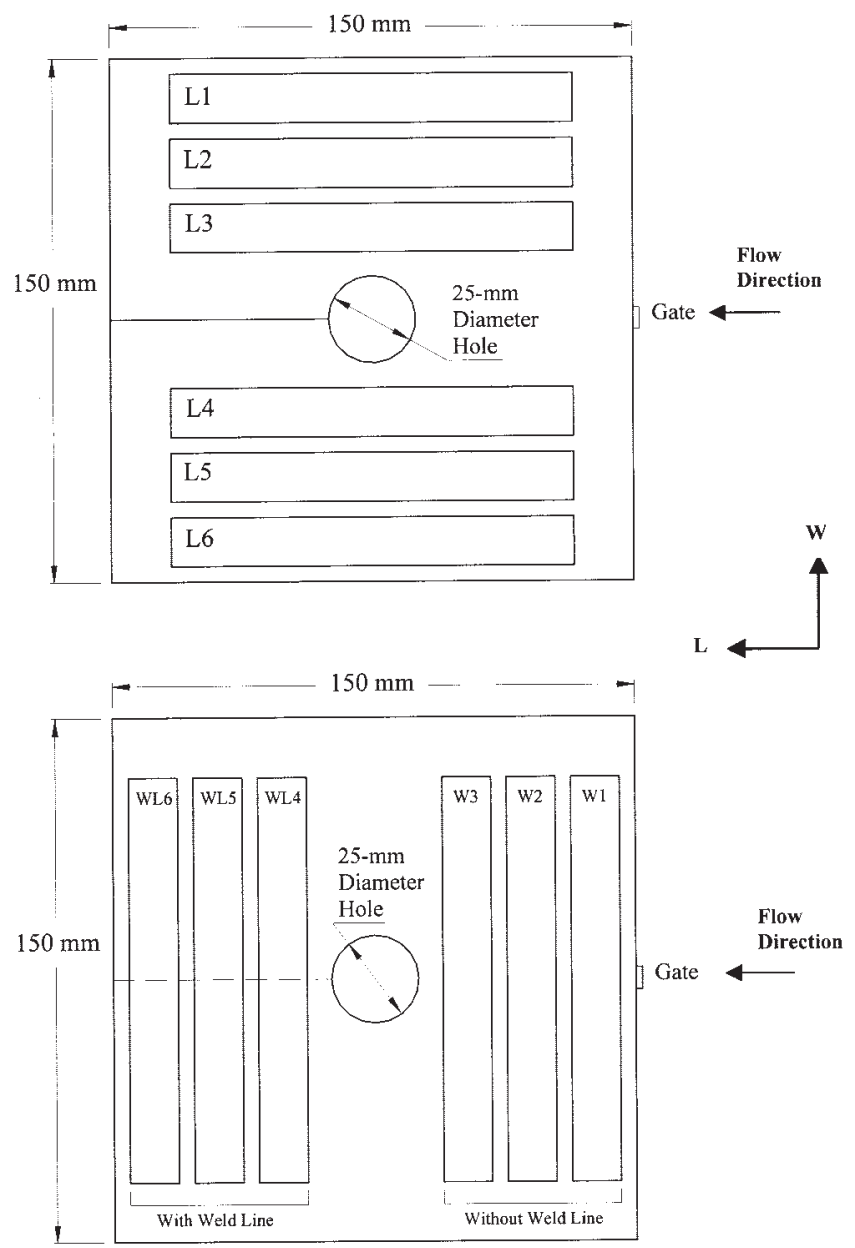

FIG. 1. Schematic of the injection molded plates showing the locations of L-direction (parallel to flow), W-direction (normal to flow), and WL (with weld line) specimens.

tion molding machine was used to mold these plates. Three different melt temperatures were considered: 209, 232, and $277^{\circ} \mathrm{C}$. The peak injection pressure was $103 \mathrm{MPa}$ for all plates, but the hold pressure was varied at three levels: 27.6, 55.2, and 82.7 MPa. The mold temperature was maintained at $35^{\circ} \mathrm{C}$. The following two groups of plates were injection molded:

(1) Group I: Hold pressure $=55.2 \mathrm{MPa}$ and melt temperature $=209,232$, and $277^{\circ} \mathrm{C}$

(2) Group II: Melt temperature $=232^{\circ} \mathrm{C}$ and hold pressure $=27.6,55.2$, and $82.7 \mathrm{MPa}$

Dog-bone-shaped specimens were prepared from the injection-molded plates in three different directions: parallel to the flow direction (L-direction specimens), normal to the flow direction (W-direction specimens), and with weld line (WL specimens). The specimen dimensions were $100 \mathrm{~mm}$ in overall length, $25 \mathrm{~mm}$ in gage length, and $12.7 \mathrm{~mm}$ in gage width. For the WL specimens, the weld line was located at the mid-length. The weld line was formed in the plates as the flow front was divided by the central core in the mold and then joined behind the core.

Uniaxial tensile tests and fatigue tests were performed on an MTS servohydraulic testing machine. The tensile tests were conducted at $1.25 \mathrm{~mm} / \mathrm{min}$, which was approximately equivalent to a strain rate of $0.05 \mathrm{~min}^{-1}$. Three tensile parameters were determined from each stressstrain curve: elastic modulus (E) from the initial slope, yield strength $\left(\sigma_{y}\right)$ corresponding to the maximum stress observed, and yield strain $\left(\epsilon_{y}\right)$ corresponding to the yield strength. Stress-controlled cyclic fatigue tests were per-

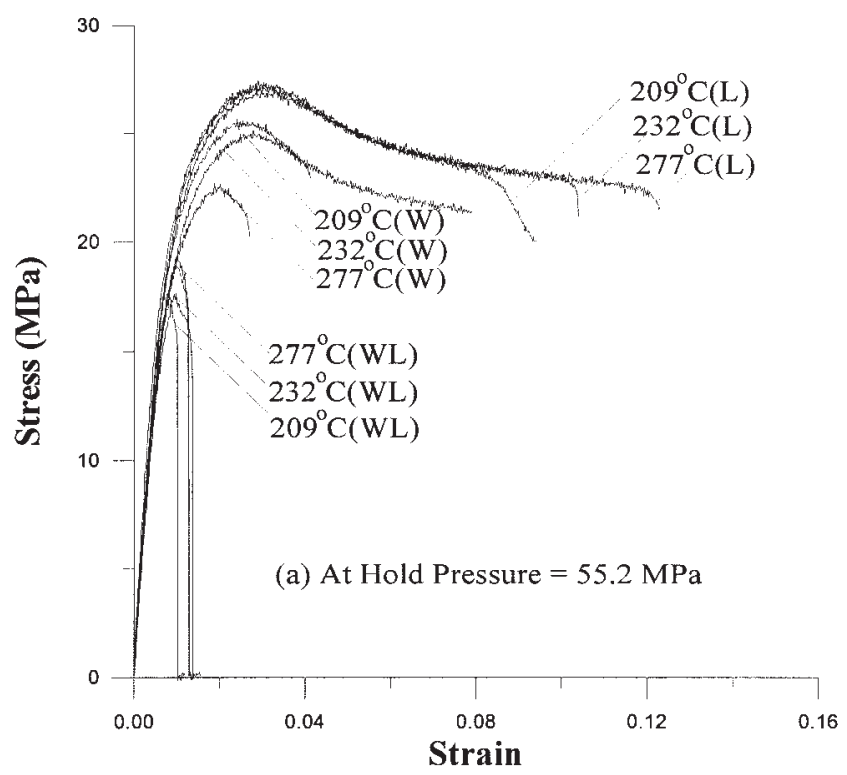

(a)

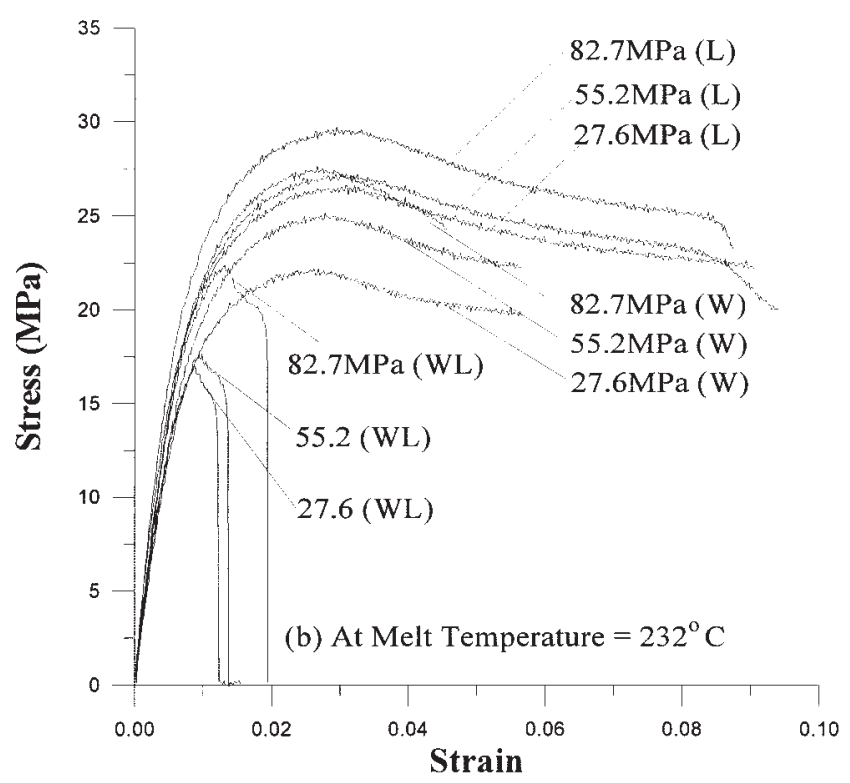

(b)

FIG. 2. Tensile stress-strain diagrams of $40 \mathrm{wt} \%$ talc-filled polypropylene (a) at the same hold pressure, but different melt temperatures and (b) at the same melt temperature, but different hold pressures (L: parallel to flow, W: normal to flow and WL: with weld line). 
.TABLE 1. Tensile and fatigue properties of $40 \mathrm{w} \%$ talc-filled polypropylene at different processing conditions.

\begin{tabular}{|c|c|c|c|c|c|c|c|}
\hline $\begin{array}{l}\text { Melt temp. } \\
\quad\left({ }^{\circ} \mathrm{C}\right)\end{array}$ & $\begin{array}{l}\text { Hold pressure } \\
\quad(\mathrm{MPa})\end{array}$ & Direction & $\begin{array}{l}\text { Tensile modulus } \\
\text { (GPa) }\end{array}$ & $\begin{array}{l}\text { Yield strength } \\
(\mathrm{MPa})\end{array}$ & $\begin{array}{c}\text { Failure strain } \\
(\%)\end{array}$ & $\sigma_{f}(\mathrm{MPa})$ & $b$ \\
\hline 209 & 55.2 & $\mathrm{~L}$ & $8.48 \pm 0.24$ & $27.03 \pm 0.16$ & $2.96 \pm 0.12$ & 32.18 & -0.0306 \\
\hline 209 & & W & $7.92 \pm 0.32$ & $25.70 \pm 0.23$ & $2.39 \pm 0.22$ & 28.49 & -0.0283 \\
\hline 209 & & WL & $6.56 \pm 0.32$ & $17.49 \pm 0.13$ & $0.79 \pm 0.10$ & 18.23 & -0.0202 \\
\hline 232 & 55.2 & $\mathrm{~L}$ & $8.62 \pm 0.13$ & $27.21 \pm 0.12$ & $2.80 \pm 0.23$ & 32.19 & -0.0312 \\
\hline 232 & & W & $7.51 \pm 0.25$ & $25.39 \pm 0.26$ & $2.57 \pm 0.14$ & 26.28 & -0.0236 \\
\hline 232 & & WL & $6.48 \pm 0.43$ & $17.88 \pm 0.22$ & $0.91 \pm 0.02$ & 19.82 & -0.0216 \\
\hline 277 & 55.2 & $\mathrm{~L}$ & $8.82 \pm 0.27$ & $27.38 \pm 0.08$ & $3.25 \pm 0.17$ & 32.58 & -0.0303 \\
\hline 277 & & $\mathrm{~W}$ & $7.41 \pm 0.36$ & $22.57 \pm 0.16$ & $1.87 \pm 0.12$ & 26.04 & -0.0277 \\
\hline 277 & & WL & $6.94 \pm 0.48$ & $19.11 \pm 0.21$ & $1.00 \pm 0.03$ & 20.73 & -0.0210 \\
\hline 232 & 27.6 & $\mathrm{~L}$ & $8.82 \pm 0.25$ & $26.61 \pm 0.02$ & $3.08 \pm 0.11$ & 31.38 & -0.0304 \\
\hline 232 & & $\mathrm{~W}$ & $7.22 \pm 0.36$ & $25.15 \pm 0.37$ & $2.69 \pm 0.12$ & 25.23 & -0.0264 \\
\hline 232 & & WL & $6.71 \pm 0.39$ & $17.06 \pm 0.24$ & $0.86 \pm 0.03$ & 18.91 & -0.0263 \\
\hline 232 & 82.7 & $\mathrm{~L}$ & $9.61 \pm 0.32$ & $29.52 \pm 0.19$ & $2.95 \pm 0.10$ & 34.91 & -0.0299 \\
\hline 232 & & W & $8.13 \pm 0.30$ & $27.62 \pm 0.26$ & $2.67 \pm 0.06$ & 29.35 & -0.0252 \\
\hline 232 & & WL & $6.92 \pm 0.26$ & $22.47 \pm 0.32$ & $1.31 \pm 0.03$ & 24.95 & -0.0247 \\
\hline
\end{tabular}

formed in tension-tension mode at an ambient temperature of $\sim 23^{\circ} \mathrm{C}$. The ratio of the minimum cyclic stress to the maximum cyclic stress (i.e., R-ratio) was 0.1 . The cyclic frequency was $1 \mathrm{~Hz}$. Such a low frequency was selected so that fatigue failure would occur instead of thermal failure [16].

\section{RESULTS}

\section{Tensile Properties}

Figure 2 shows the tensile stress-strain curves of the 40 wt $\%$ talc-filled polypropylene specimens parallel to the flow direction (L), normal to the flow direction (W), and with weld line (WL) under the different processing conditions considered. It can be observed in these figures that the stress-strain relationships were nonlinear even at strains lower than the yield strain. Each curve shows a maximum stress, which was assumed to be the yield strength of the material. After reaching the maximum stress, the specimen with the weld line failed almost immediately; however, for the L-direction and W-direction specimens, stress decreased steadily with strain until fracture occurred. The mean value and the standard deviation of the tensile properties obtained from three specimens for different processing conditions are listed in Table 1. The yield strength in the L-direction was higher than that in the W-direction. The difference in properties in these two mutually perpendicular directions indicates inherent anisotropy of the injection-molded talc-filled polypropylene plates. The presence of weld line in WL specimens significantly decreased the yield strength and failure strain. However, the weld line did not influence the modulus.

Figure 2a shows the effect of melt temperature on the tensile behavior of the talc-filled polypropylene. The hold pressure for these specimens was 55.2 MPa. For specimens parallel to the flow direction, the yield strengths at different

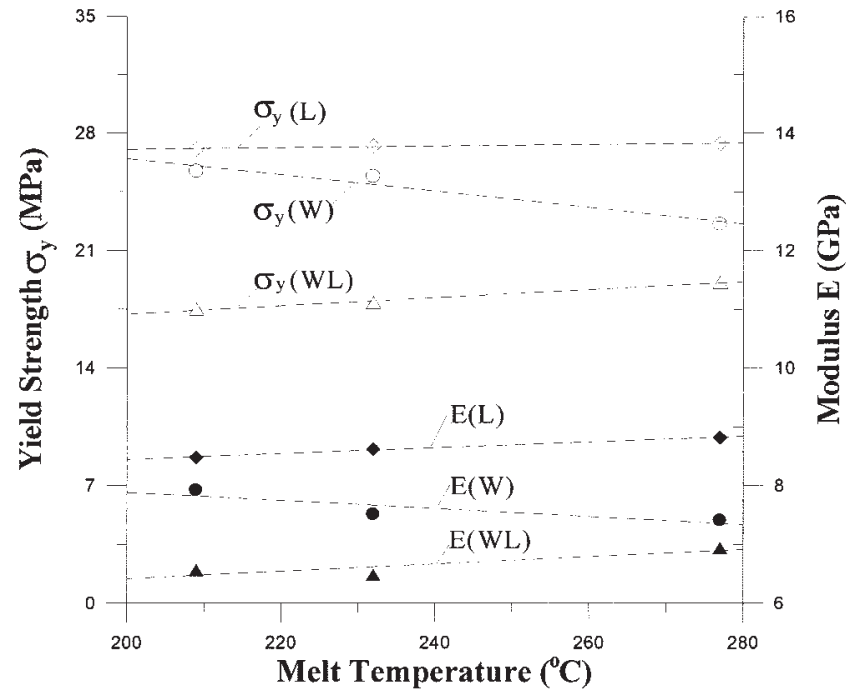

(a)

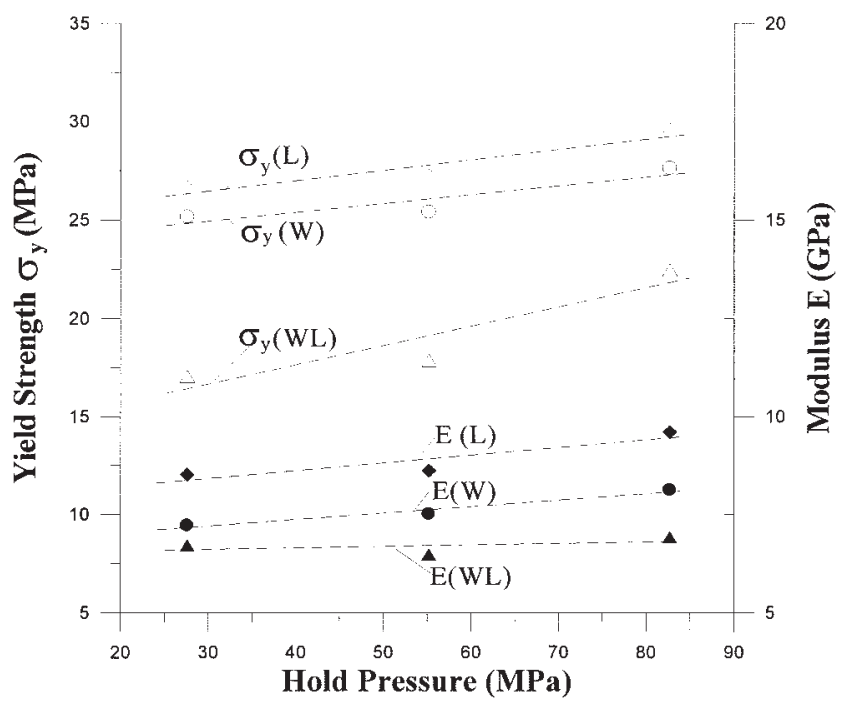

(b)

FIG. 3. Effect of (a) melt temperature and (b) hold pressure on yield strength and modulus of $40 \mathrm{wt} \%$ talc-filled polypropylene (L: parallel to flow, W: normal to flow and WL: with weld line). 
TABLE 2. Processing condition factors of $40 \mathrm{w} \%$ talc-filled polypropylene.

\begin{tabular}{|c|c|c|c|c|}
\hline Property & Parameter & In the flow $(\mathrm{L})$ direction & Normal to the flow (W) direction & With weld line \\
\hline \multirow[t]{4}{*}{ Yield strength } & $J_{\text {melt }}$ & 0.0050 & -0.048 & 0.024 \\
\hline & $J_{\text {pressure }}$ & 0.53 & 0.45 & 0.98 \\
\hline & $L_{\text {melt }}$ & 0.0049 & -0.0068 & 0.0062 \\
\hline & $L_{\text {pressure }}$ & 0.20 & 0.17 & 0.038 \\
\hline \multirow[t]{3}{*}{ Fatigue strength } & $K_{\text {melt }}$ & 0.011 & -0.032 & 0.034 \\
\hline & $K_{\text {pressure }}$ & 0.64 & 0.75 & 1.10 \\
\hline & $b$ & -0.031 & -0.027 & -0.023 \\
\hline
\end{tabular}

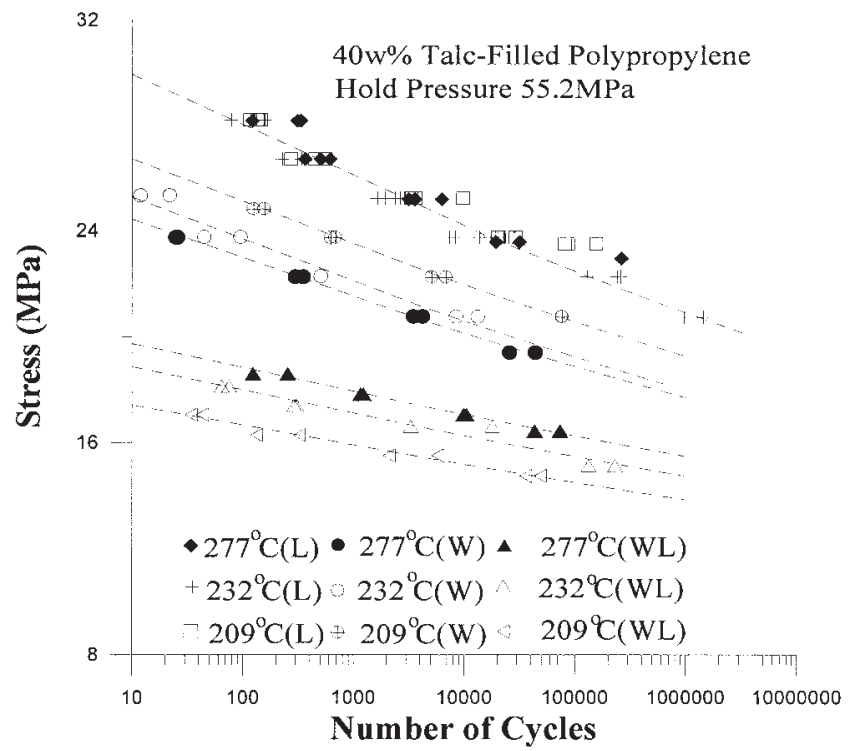

(a)

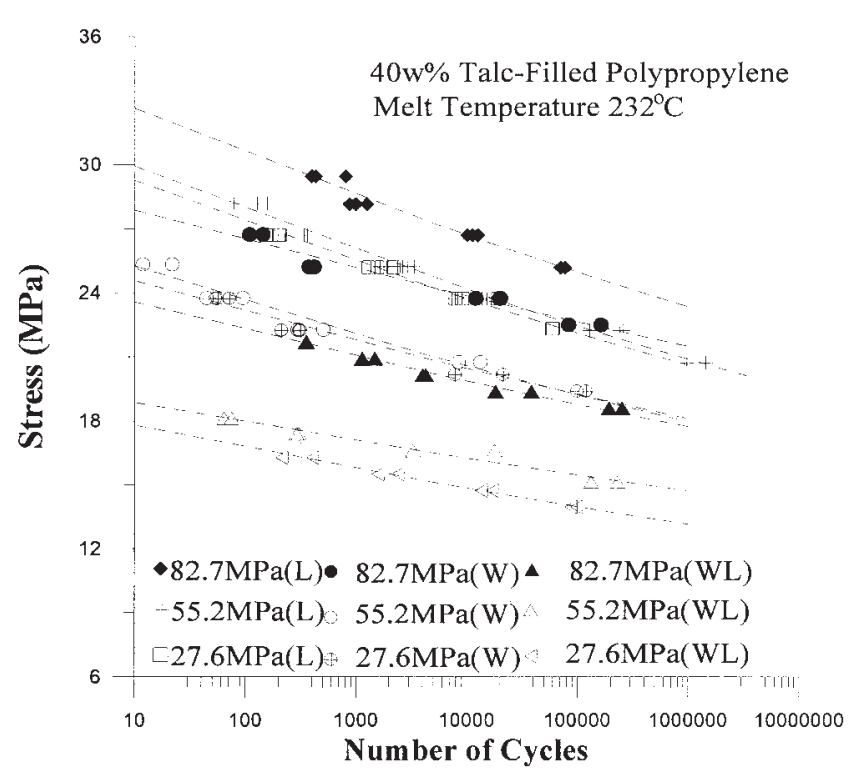

(b)

FIG. 4. S-N diagrams of $40 \mathrm{wt} \%$ talc-filled polypropylene (a) at the same hold pressure, but different melt temperatures and (b) at the same melt temperature, but different hold pressures (L: parallel to flow, W: normal to flow and WL: with weld line). melt temperatures were very close and the stress-strain curves after yielding did not show much difference. For specimens normal to the flow direction, the yield strength and stress level after yielding were significantly lower at melt temperature $277^{\circ} \mathrm{C}$. The tensile orientation factor, defined as the ratio of yield strengths of the L-direction and the $\mathrm{W}$-direction specimens, changed from 1.05 at melt temperature $209^{\circ} \mathrm{C}$ to 1.27 at melt temperature $277^{\circ} \mathrm{C}$. For specimens with weld line, yield strength increased with increasing melt temperature. The tensile weld line factor, defined as the ratio of the yield strengths of the L-direction specimens and the WL specimens, was 1.55 at melt temperature $209^{\circ} \mathrm{C}$ and decreased to 1.43 at melt temperature $277^{\circ} \mathrm{C}$.

Figure $2 \mathrm{~b}$ shows the effect of hold pressure on the tensile behavior of the talc-filled polypropylene. The melt temperature for these specimens was $232^{\circ} \mathrm{C}$. Increasing the hold pressure increased the yield strengths for all three types of specimens. But the anisotropy of the talc-filled polypropylene was not very sensitive to hold pressure. The tensile orientation factors were 1.06, 1.06, and 1.07 at hold pressure 27.6 MPa, 55.2 MPa, and 82.7 MPa, respectively. However, the weld-line strength increased with increasing hold pressure. The tensile weld line factor dropped from 1.56 at hold pressure 27.6 MPa to 1.31 at hold pressure $82.7 \mathrm{MPa}$.

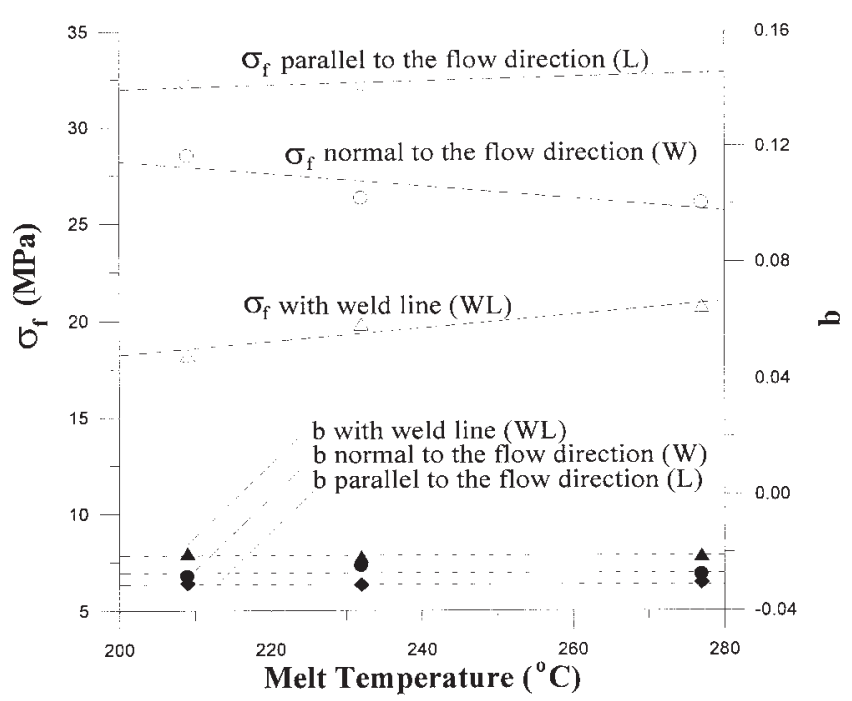

FIG. 5. Effect of melt temperature on the fatigue strength coefficient $\sigma_{f}$ and fatigue strength exponent $b$ (L: parallel to flow, W: normal to flow and WL: with weld line). 


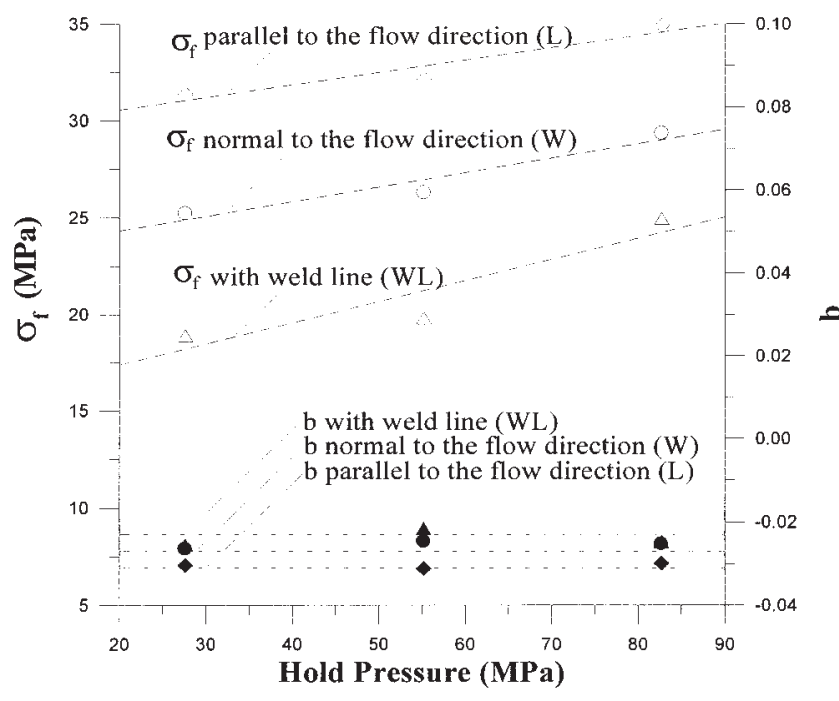

FIG. 6. Effect of hold pressure on the fatigue strength coefficient $\sigma_{f}$ and fatigue strength exponent $b$ (L: parallel to flow, W: normal to flow and WL: with weld line).
Figure 3 shows that both tensile modulus and yield strength of the talc-filled polypropylene varied linearly with melt temperature and hold pressure. The linear relationships observed in these plots are modeled with the following equations:

$$
\begin{gathered}
\sigma_{Y}=\sigma_{Y 0}\left[1+J_{\text {melt }}\left(T-T_{0}\right)\right]\left[1+J_{\text {pressure }}\left(P-P_{0}\right)\right] \\
E=E_{0}\left[1+L_{\text {melt }}\left(T-T_{0}\right)\right]\left[1+L_{\text {pressure }}\left(P-P_{0}\right)\right]
\end{gathered}
$$

where $J_{\text {melp }}, L_{\text {melt }}$ and $J_{\text {pressure }}, L_{\text {pressure }}$ are melt temperature sensitivity factors and hold pressure sensitivity factors, $T_{0}$ and $P_{0}$ are the reference melt temperature and reference mold pressure, and $\sigma_{Y 0}$ and $E_{0}$ are the reference yield strength and modulus. The average values of $J_{\text {melt }}$, $L_{\text {melt }}$, $J_{\text {pressure }}$ and $L_{\text {pressure }}$ are listed in Table 2 .

\section{Fatigue Properties}

Figure 4 shows the $\mathrm{S}-\mathrm{N}$ curves of the $40 \mathrm{wt} \%$ talc-filled polypropylene parallel to the flow direction (L), normal to the flow direction (W), and with weld line (WL) at different

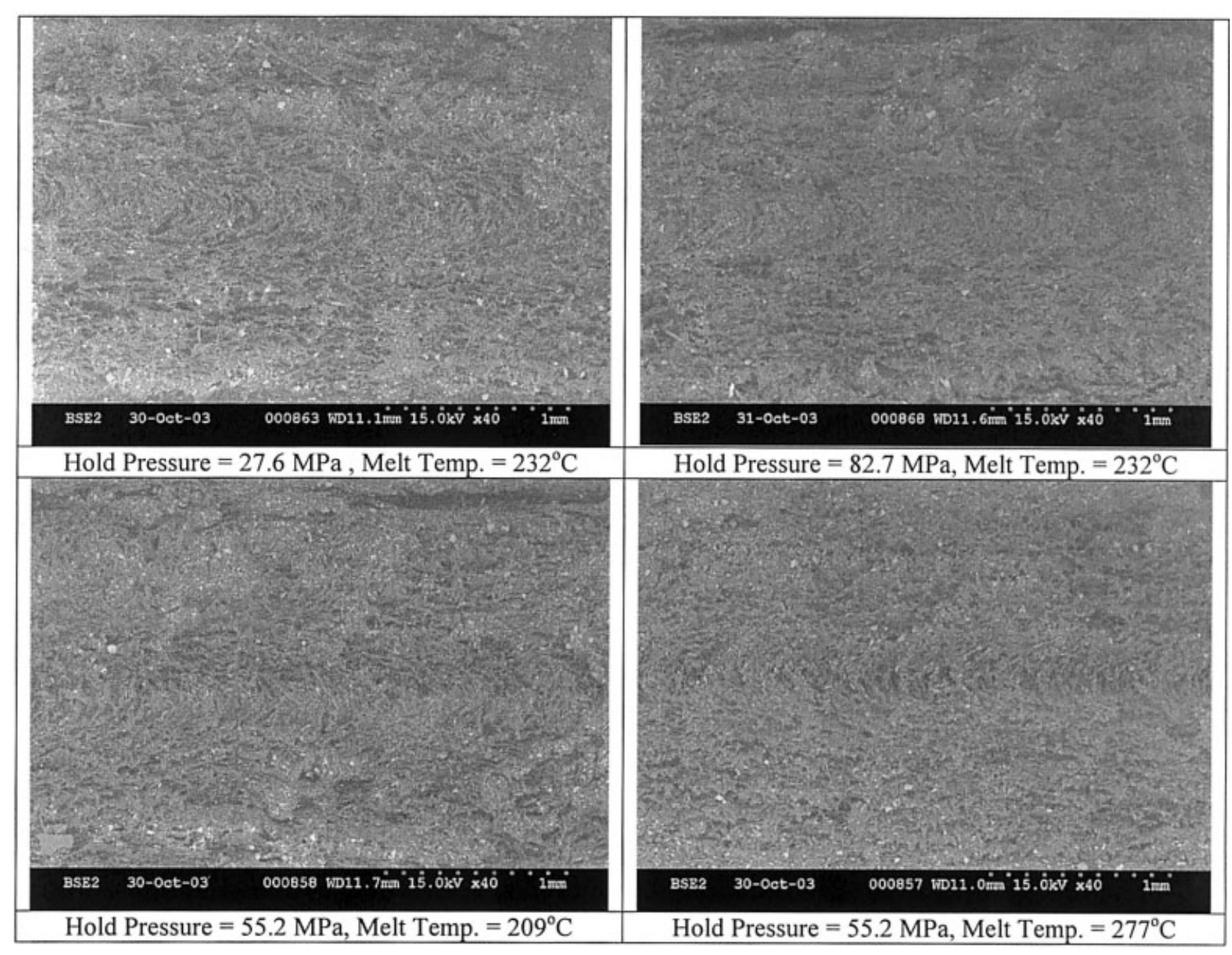

FIG. 7. SEM photographs of fatigue fracture surfaces of L-direction (parallel to flow) specimens at different melt temperatures and hold pressures (at $40 \times$ ). 


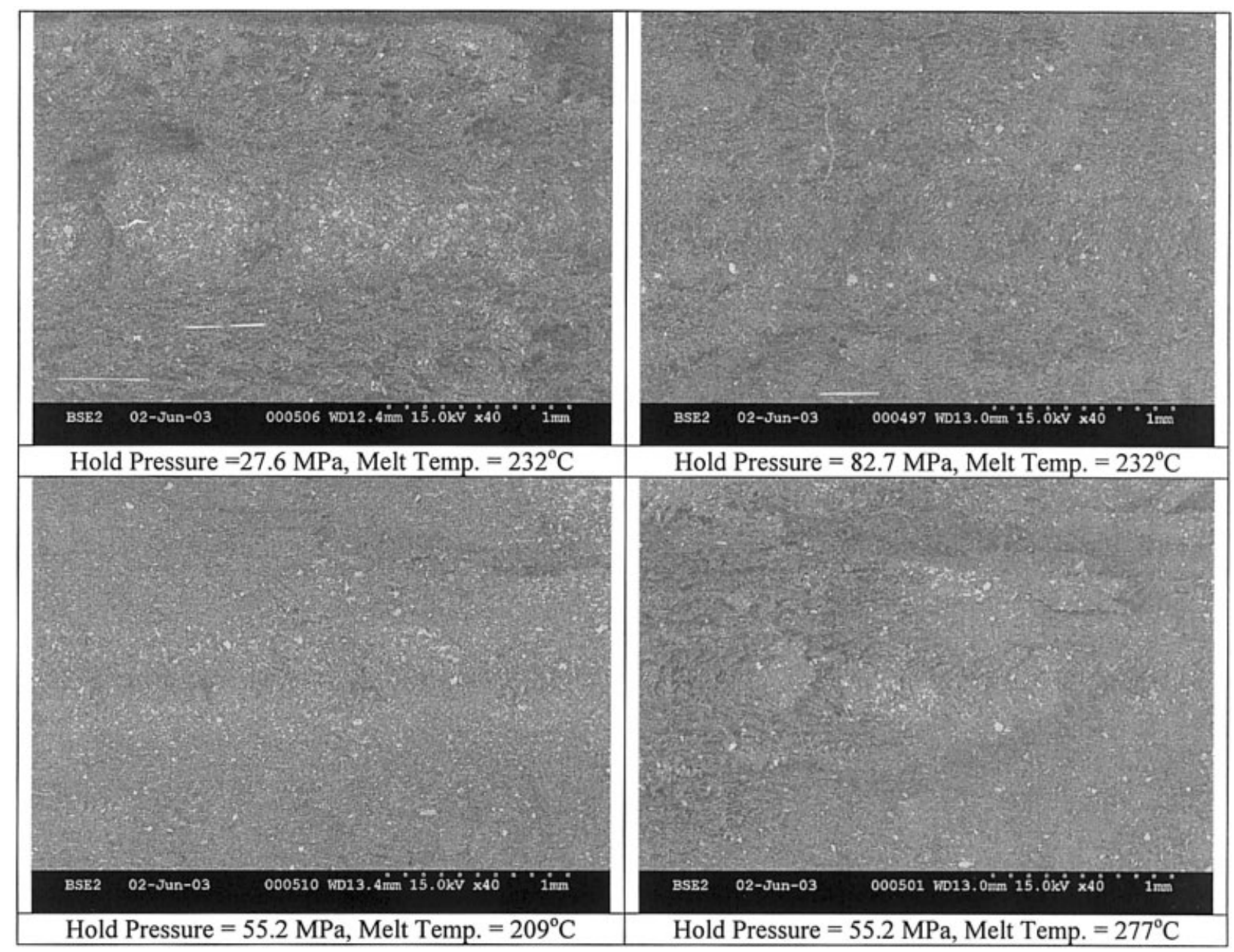

FIG. 8. SEM photographs of fatigue fracture surfaces of W-direction (normal to flow) specimens at different melt temperatures and hold pressures (at $40 \times$ ).

melt temperatures. The hold pressure for these specimens was 55.2 MPa. The fatigue strength in L-direction was much higher than that in the $\mathrm{W}$-direction. The presence of weld line decreased the fatigue strength even further. Similar to the tensile test results, melt temperature did not have any effect on the fatigue strength of the L-direction specimens. However, for the $\mathrm{W}$-direction specimens fatigue strength decreased with increasing melt temperature and for the WL specimens, fatigue strength increased with increasing melt temperature.

Figure 4 also shows the effect of hold pressure on the fatigue behavior of the talc-filled polypropylene. The melt temperature in this case was $232^{\circ} \mathrm{C}$. As before, the Ldirection specimens had the highest fatigue strength and the WL specimens had the lowest fatigue strength. The fatigue strength for all three types of specimens increased with increasing hold pressure. The highest increase occurred when the hold pressure was increased from 55.2 to 82.7 MPa.

Based on the experimental results, the following empirical equation, similar to the Basquin equation used for stress-life data of metals [17], was fitted to the S-N curves corresponding to each processing condition:

$$
\sigma=\sigma_{f}\left(N_{f}\right)^{b}
$$

where, $\sigma=$ fatigue stress level, $N_{f}=$ number of cycle to failure at $\sigma, \sigma_{f}=$ fatigue strength coefficient, $b=$ fatigue strength exponent. The values of fatigue strength coefficient $\sigma_{f}$ and fatigue strength exponent $b$ at different processing conditions are listed in Table 1 and are plotted in Figs. 5 and 6 as a function of melt temperature and hold pressure, respectively.

Figure 5 shows that $\sigma_{f}$ for the L-direction specimens and WL specimens increased with increasing melt temperature, while $\sigma_{f}$ for the W-direction specimens decreased with increasing melt temperature. Figure 5 also shows that the variation of fatigue strength exponent $b$ with melt temperature was very small, and therefore, in the melt temperature range considered, $b$ was assumed to be a constant. Figure 6 shows the variation of fatigue strength coefficient $\sigma_{f}$ and 


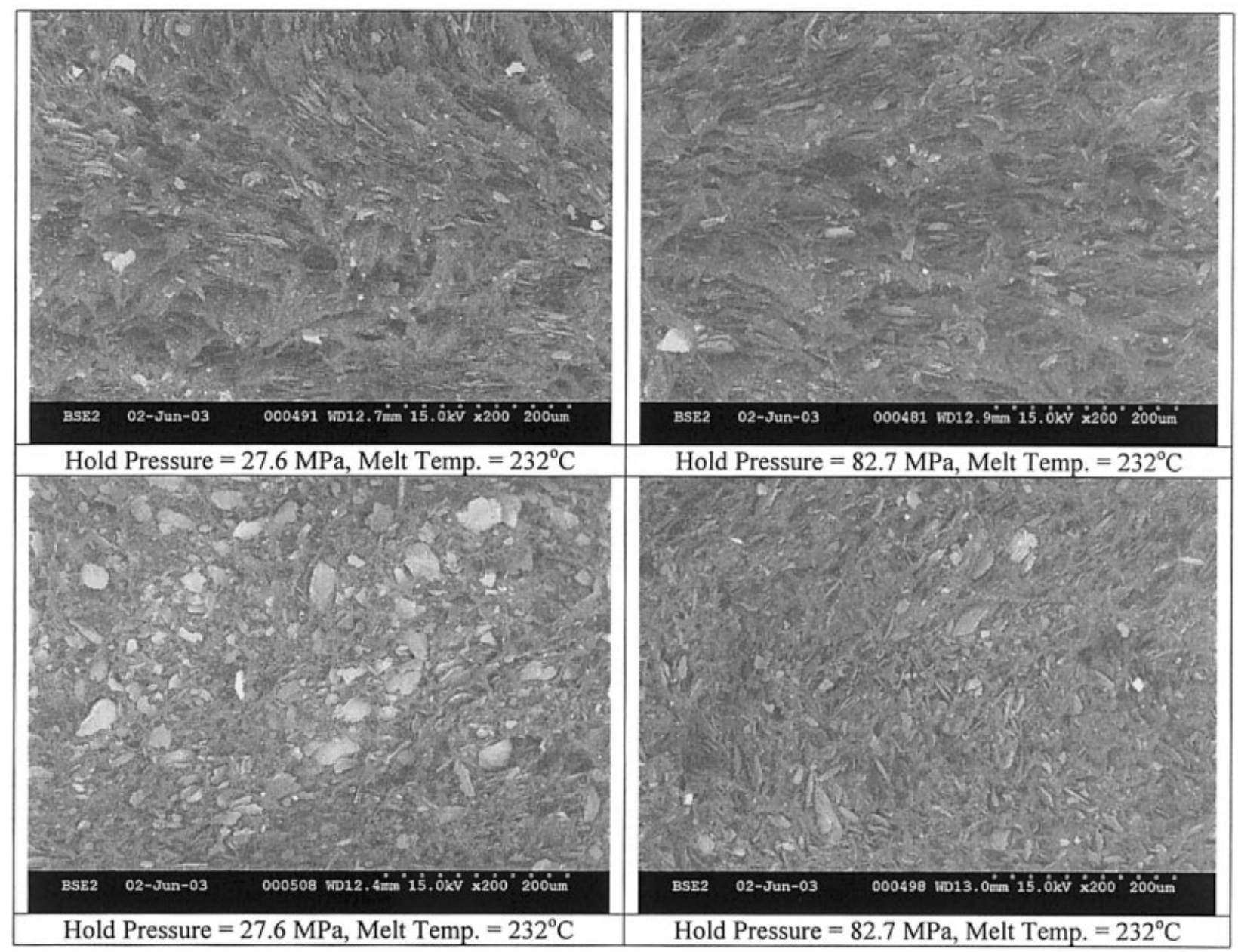

FIG. 9. SEM photographs of the center section of the fatigue fracture surfaces of L-direction (top) and $\mathrm{W}$-direction (bottom) specimens at $232^{\circ} \mathrm{C}$ melt temperature and two different hold pressures (27.6 MPa and 82.7 MPa) (at $200 \times)$.

fatigue strength exponent $b$ with hold pressure. The values of $\sigma_{f}$ for all three types of specimens increased with increasing hold pressure; however, the fatigue strength exponent $b$ was not much affected by hold pressure. Thus, in the range of hold pressures considered, $b$ was assumed to be a constant. The following empirical relationship was found to fit the combined effect of melt temperature and hold pressure on $\sigma_{f}$ :

$$
\sigma_{f}=\sigma_{f 0}\left[1+K_{\text {melt }}\left(T-T_{0}\right)\right]\left[1+K_{\text {pressure }}\left(P-P_{0}\right)\right]
$$

where $K_{\text {melt }}$ and $K_{\text {pressure }}$ are melt temperature sensitivity factor and hold pressure sensitivity factor in fatigue, $T_{0}$ and $P_{0}$ are reference melt temperature and reference mold pressure, and $\sigma_{f 0}$ is the reference fatigue strength coefficient. The average values of $K_{\text {melt }}, K_{\text {pressure }}$ and $b$ of the talc-filled polypropylene are listed in Table 2 . The value of $K_{\text {melt }}$ with weld line was much higher than that in the flow direction and the $K_{\text {melt }}$ normal to the flow direction was negative. The values of $K_{\text {pressure }}$ in the flow direction and normal to the flow direction were close, but $K_{\text {pressure }}$ with weld line was higher than that in the flow direction and normal to the flow direction.

\section{Fracture Surface Observations}

The fracture surfaces of several fatigue specimens were examined under scanning electron microscope to determine the differences in the L-direction, W-direction, and WL specimens. Each fracture surface exhibited skincore morphology with different degrees of talc particle orientations in the core and in the skin. The relative size of the core and the skin varied with processing condition. In general, the greater the talc particle orientation parallel to the loading direction, the higher will be strength, since they are more effective in stress transfer than those oriented normal to the loading direction. The processing condition also affects the molecular orientation and crystalline morphology in the skins and core of injectionmolded polypropylene; however, their effects on mechanical properties may be of less importance than the 


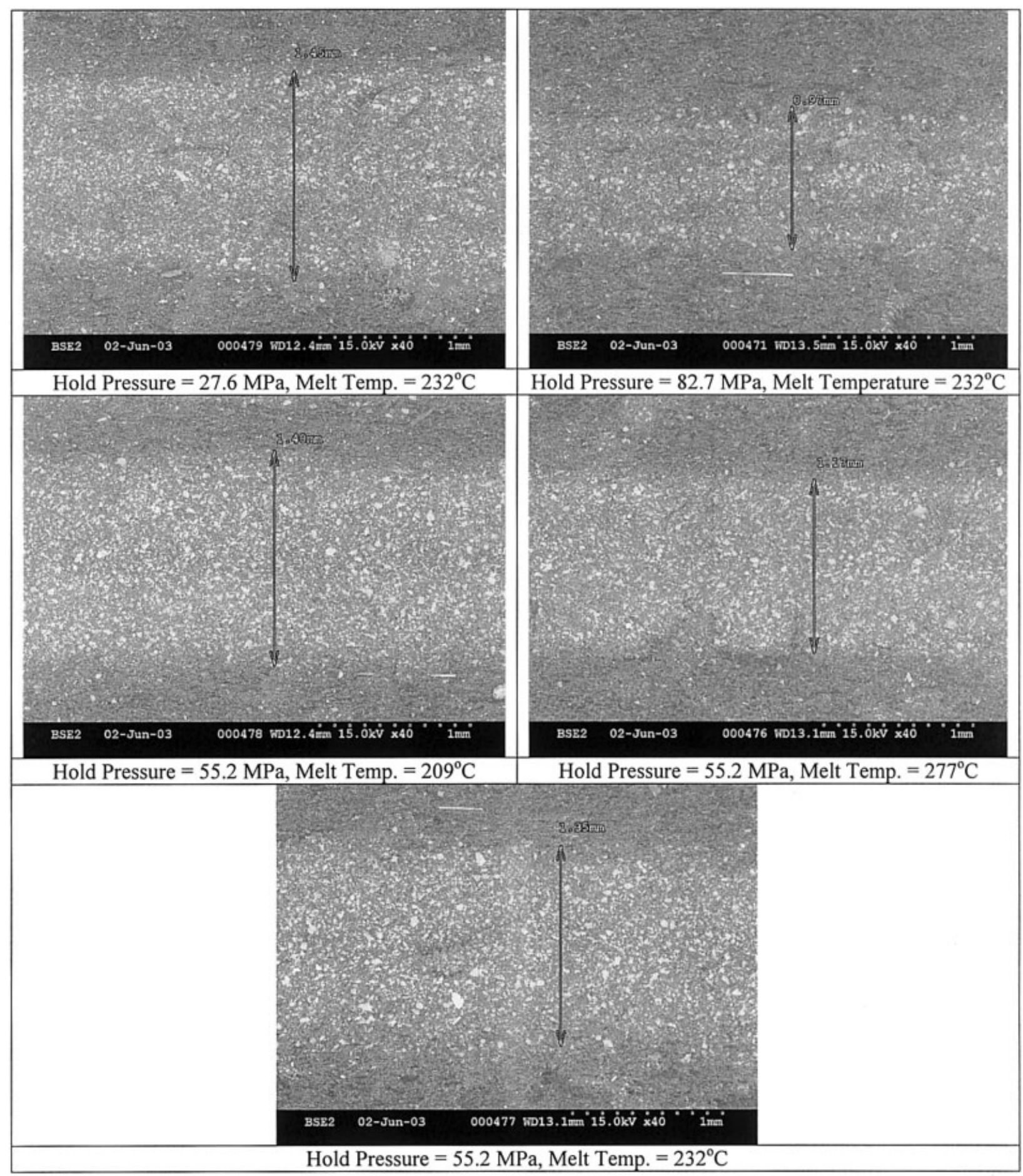

FIG. 10. SEM photographs of fatigue fracture surfaces of WL specimens (with weld line) at different melt temperatures and hold pressures (at $40 \times$ ).

effect of filler orientation in a highly filled polypropylene [6].

Figure 7 shows the fracture surfaces of the L-direction specimens at different processing conditions. On each fracture surface, there was evidence of skin-core morphology, with the skins containing many talc particles oriented normal to the loading direction. Talc particles in the core were oriented parallel to the loading direction, which was also the flow direction for the specimens. The parabolic flow pattern in the core was also clearly visible in Figure 7. The skins were relatively thin compared to the core and their thickness did not change much with melt temperature. However, the skin thickness decreased with increasing hold pressure.

Skin-core morphology was also found on the fatigue fracture surfaces of the specimens normal to the flow direc- 
TABLE 3. Effect of melt temperature and hold pressure on the core and skin thickness values in the weld-line specimens.

\begin{tabular}{cccc}
\hline $\begin{array}{c}\text { Melt temp. } \\
\left({ }^{\circ} \mathrm{C}\right)\end{array}$ & $\begin{array}{c}\text { Hold pressure } \\
(\mathrm{MPa})\end{array}$ & $\begin{array}{c}\text { Approx. core } \\
\text { thickness }(\mathrm{mm})\end{array}$ & $\begin{array}{c}\text { Approx. total skin } \\
\text { thickness }(\mathrm{mm})\end{array}$ \\
\hline 209 & 55.2 & 1.40 & 1.10 \\
232 & 55.2 & 1.35 & 1.15 \\
277 & 55.2 & 1.17 & 1.33 \\
232 & 27.6 & 1.45 & 1.05 \\
232 & 55.2 & 1.35 & 1.15 \\
232 & 82.7 & 0.97 & 1.53 \\
\hline
\end{tabular}

tion (Fig. 8). In this case, many talc particles in the core were oriented normal to the loading direction (Fig. 9). With increasing hold pressure, the talc particle orientation normal to the loading direction was reduced, which explains the increase in yield strength and fatigue strength of these specimens at higher hold pressure.

Figure 10 shows the fracture surfaces of WL specimens containing a weld line. In these specimens, the skin-core morphology was very clearly visible. The white band in the core contained talc particles that were oriented normal to the loading direction. The darker zones in the skins contained talc particles oriented parallel to the loading direction. The thickness of the core decreased and the thickness of the skins increased with increasing melt temperature and increasing hold pressure (Table 3). This explains the reason for increasing yield strength and fatigue strength with either increasing melt temperature or increasing hold pressure.

\section{CONCLUSIONS}

Static tensile and fatigue tests were performed on 40 wt $\%$ talc-filled polypropylene injection molded at three different melt temperatures and three different hold pressures. It was observed that yield strength and fatigue strength of the talc-filled polypropylene specimens were lower normal to the flow direction than in the flow direction, indicating inherent anisotropy in the material. Yield strength and fatigue strength of the talc-filled polypropylene with weld line were significantly lower than those without weld line. Yield strength and fatigue strength of the talcfilled polypropylene in the flow direction was not influenced by melt temperature, but they increased with increasing hold pressure. Yield strength and fatigue strength of the talcfilled polypropylene normal to the flow direction decreased with increasing melt temperature, but they increased with increasing hold pressure. Yield strength and fatigue strength of the talc-filled polypropylene with weld line increased with increasing melt temperature as well as increasing hold pressure. Both melt temperature and hold pressure influenced skin-core morphology exhibiting different orientations of talc particles in the skins than in the core.

\section{REFERENCES}

1. J.P. Trotignon, L. Demdoum, and J. Verdu, Composites, 23, 313 (1992).

2. J.P. Trotignon, L. Demdoum, and J. Verdu, Composites, 23, 319 (1992).

3. S.-Y. Fu, B. Lauke, E. Mäder, C.-Y. Yue, and X. Hu, Composites, Part A, 31, 1117 (2000).

4. J.L. Thomason, M.A. Vlug, G. Schipper, and H.G.L.T. Krikor, Composites, Part A, 27A, 1075 (1996).

5. J.L. Thomason and M.A. Vlug, Composites, Part A, 28A, 277 (1997).

6. M. Fujiyama, H. Awaya, and S. Kimura, J. Appl. Polym. Sci., 21, 3291 (1977).

7. G. Kalay and M. J. Bevis, J. Polym. Sci.: Part B: Polym. Phys., 35, 241 (1997).

8. R. Mendoza, G. Régnier, W. Seiler, and J.L. Lebrun, Polymer, 44, 3363 (2003).

9. G. Kalay and M. J. Bevis, J. Polym. Sci.: Part B: Polym. Phys., 35, 265 (1997).

10. M. Akay and D. Barkley, J. Matl. Sci., 26, 2731 (1991).

11. J.-P. Tancrez, J. Pabiot, and F. Rietsch, Comp. Sci. and Tech., 56, 725 (1996).

12. P. Davé and D. Chundury, J. Inj. Molding Tech., 1, 181 (1997).

13. G. Guerrica-Echevaría, J.I. Eguiazábal, and J. Nazábal, Eur. Polym. J., 34, 1213 (1998).

14. S. Díez-Gutiérrez, M.A. Rodríguez-Pérez, J.A. De Saja, and J.I. Velasco, Polymer, 40, 5345 (1999).

15. S. Díez-Gutiérrez, M.A. Rodríguez-Pérez, J.A. De Saja, and J.I. Velasco, J. Appl. Polym. Sci., 77, 1275 (2000).

16. Y. Zhou and P.K. Mallick, Polym. Eng. Sci., 45, 510 (2004).

17. J.A. Bannantine, J.J. Comer, and J.L. Handrock, Fundamentals of Metal Fatigue Analysis, Prentice Hall, New York (1990). 